\title{
PROBLEMATIKA PENGKADERAN DI PERGURUAN TINGGI MUHAMMADIYAH MATARAM DALAM PERSPEKTIF NORMA PENGKADERAN MUHAMMADIYAH
}

\author{
Mappanyompa $^{1}$ \\ Dosen Fakultas Agama Islam Universitas Muhammadiyah Mataram \\ Email1: Myompakaltim@gmail.com \\ Imawanto ${ }^{2}$ \\ Dosen Fakultas Hukum Universitas Muhammadiyah Mataram \\ Email2: imawanto123@gmail.com \\ DOI: https://doi.org/10.31764/jmk.v10i1.1106
}

Received: Des 28, 2018, Accepted: Feb 9, 2019 /Published: April 30, 2019

\begin{abstract}
This article discusses the problem of cadre formation in Muhammadiyah Mataram universities in the perspective of cadre norms. In full, cadres are those who have been completed in following all formal cadres, tested in informal cadres and have provisions through informal formation. Their existence is not only expected in the existence of the organization to be maintained, but also expected that the cadres will continue to carry out the mission of the organization's movement to the full. This type of research is quantitative explanatory research, with data collection techniques through library research and field work research. The results of the study show that regeneration occupies a very strategic position for the survival of Muhammadiyah as a community and Islamic missionary movement Amar Ma'ruf Nahi Munkar. Cadreization must be of serious concern from all Muhammadiyah leaders and Muhammadiyah's charitable business leaders, especially in West Nusa Tenggara. The foundation of sincere intention to live Muhammadiyah and not only seek life in the Muhammadiyah as the message of the founder of the late KH. Ahmad Dahlan. The origins of the Kemuhammadiyahan strategic position holder in the Muhammadiyah charity business must be directly proportional to the cadre process that has been traversed on the basis of commitment and the complete and complete cadre norm.
\end{abstract}

Keywords: cadre norms; cadre problems; Muhammadiyah universities.

\begin{abstract}
ABSTRAK
Artikel ini membahas tentang problematika pengkaderan di Perguruan Tinggi Muhammadiyah Mataram perspektif norma pengkaderan. Secara utuh kader adalah mereka yang telah tuntas dalam mengikuti seluruh pengkaderan formal, teruji dalam pengkaderan informal dan memiliki bekal melalui pengkaderan non formal. Keberadaan mereka bukan saja diharapkan dalam eksistensi organisasi tetap terjaga, melainkan juga diharapkan kader tetap akan membawa misi gerakan organisasi hingga paripurna. Jenis penelitian ini adalah penelitian eksplanatif kuantitatif,
\end{abstract}


dengan teknik pengumpulan data melalui library research dan field work research. Hasil penelitian menunjukkan bahwa kaderisasi menempati posisi yang sangat strategis bagi kelangsungan hidup Muhammadiyah sebagai sebuah persyarikatan dan gerakan Islam dakwah amar ma' ruf nahi munkar. Kaderisasi menjadi perhatian yang sungguh-sungguh dari segenap pimpinan Muhammadiyah dan pimpinan amal usaha Muhammadiyah, terutama di Nusa Tenggara Barat. Landasan niat yang tulus untuk menghidup-hidupkan Muhammadiyah dan tidak semata mencari hidup dalam Muhammadiyah sebagaimana pesan sang pendirinya almarhum KH. Ahmad Dahlan. Asal-usul kemuhammadiyahan pemegang jabatan strategis di amal usaha Muhammadiyah harus berbanding lurus dengan proses pengkaderan yang telah dilalui atas dasar komitment dan norma pengkaderan secara tuntas dan paripurna.

Kata kunci: norma pengkaderan; perguruan tinggi Muhammadiyah; problematika pengkaderan.

\section{PENDAHULUAN}

Persyarikatan Muhammadiyah yang melintasi perjalanan usia satu abad senantiasa bersinggungan dan memiliki kaitan dengan berbagai permasalahan yang sedang dihadapi oleh umat manusia saat ini, baik dalam lingkup nasional maupun global, termasuk di dalamnya dinamika kehidupan umat Islam. Posisi Muhammadiyah dalam dinamika dan permasalahan kehidupan nasional, global, dan dunia Islam sebagaimana digambarkan di atas dibingkai dan ditandai dengan lima peran yang secara umum menggambarkan misi Persyarikatan.

Peran global tersebut merupakan keniscayaan karena di satu pihak Muhammadiyah merupakan bagian dari dunia global, di pihak lain perkembangan dunia di tingkat global tersebut masih ditandai oleh berbagai persoalan dan krisis yang mengancam kelangsungan hidup umat manusia dan peradabannya karena keserakahan negara-negara maju yang melakukan eksploitasi di banyak aspek kehidupan. Sejarah menunjukkan bahwa Muhammadiyah sebagai gerakan Islam rentang usia satu abad telah berkiprah optimal untuk memajukan kehidupan umat Islam dan 
bangsa Indonesia, yang memberi makna bagi kehidupan umat manusia pada umumnya. ${ }^{1}$

Muhammadiyah telah berjuang melalui gerakan dakwah dan tajdid dalam usaha pembinaan kehidupan beragama sejalan dengan Al-Quran dan Sunnah Nabi serta melakukan usaha-usaha pembaruan kemasyarakatan melalui pendidikan, pelayanan kesehatan, pelayanan sosial, pemberdayaan masyarakat, peran politik kebangsaan, dan sebagainya, yang merupakan perwujudan untuk membentuk masyarakat Islam yang sebenar-benarnya dan menghadirkan Islam sebagai rahmat bagi semesta alam. ${ }^{2}$

Satu lembaga pendidikan Islam yang bercorak modern adalah lembaga Islam Muhammadiyah. Lembaga ini didirikan oleh Ahmad Dahlan dengan tujuan mencerdaskan umat Islam melalui pendidikan. Sejak dari awal pendirian, Muhammadiyah telah menempatkan pendidikan sebagai salah satu media untuk mencapai tujuan organisasi ini yakni untuk menyerukan pentingnya kembali pada Al Qur'an dan Sunnah sebagai usaha mengatasi perbuatan menyimpang dalam kehidupan beragama umat Islam di Indonesia yang melakukan praktik takhayul, bid'ah, dan kurafat dengan tidak mendasarkan dirinya pada madzhab atau pemikiran tertentu. ${ }^{3}$ Lewat pendidikan, Muhammadiyah mampu mencerdaskan umat Islam dan bangsa Indonesia. Dari semua tujuan berdirinya Muhammadiyah tentu ada beberapa permasalahan yang bermunculan. baik dari dalam tubuh Muhammadiyah itu sendiri maupun dari faktor luar Muhammadiyah, yang mana permasalahan tersebut juga dapat mempengaruhi perkembangan Muhammadiyah

\footnotetext{
1 Pasha, Musthafa Kamal dan Darban, Ahmad Adaby, Muhammadiyah sebagai Gerakan Islam (dalam Perspektif Historis dan Ideologis), LPPI UMY, Yogyakarta, 2000.

2 M. Amin, Rais, Tauhid Sosial, Formula Menggempur Kesenjangan, Mizan), Bandung, 1998.

${ }^{3}$ Hambali, Hamdan, Ideologi dan Stategi Muhammaadiyah, Suara Muhammadiyah, Yogyakarta, 2006.
} 
sebagai suatu organisasi dan juga badan usaha. Berdasarkan beberapa permasalahan yang bergejolak di Muhammadiyah tersebut, adalah suatu bahasan yang menarik untuk dibahas secara mendalam.

Sejarah Berdirinya Muhammadiyah yaitu pada awal abad ke $20 \mathrm{M}$, dikalangan muslim Indonesia terpelajar mulai muncul kesadaran baru untuk mengatasi kondisi pendidikan Islam di Indonesia yang mengalami keterbelakangan akibat tidak mampu bersaing dengan lembaga pendidikan yang diselenggarakan oleh pemerintah kolonial Belanda, yang mencetak tenaga kerja terampil tetapi mengabaikan pendidikan moral peserta didik. Oleh karena itu, mereka mengupayakan mendirikan lembaga pendidikan Islam yang bercorak modern. Salah satu lembaga pendidikan Islam yang bercorak modern adalah lembaga Islam Muhammadiyah. Lembaga ini didirikan oleh Ahmad Dahlan dengan tujuan mencerdaskan umat Islam melalui pendidikan. Karena Ahmad Dahlan termasuk anggota organisasi Budi Utomo maka sebelum mendirikan lembaga pendidikan Islam Muhammadiyah, beliau meminta restu kepada Budi Utomo. Setelah itu, beliau membuka sekolah agama di rumahnya dengan nama Madrasah Ibtidaiyah Diniyah Islamiah. Awal lembaga pendidikan Islam ini berdiri hanya memiliki delapan orang murid. Karena penyampaian materi dari Ahmad Dahlan yang menarik, setiap bulan muridnya bertambah tiga orang. Melihat kemajuan pendidikan lembaga tersebut maka Budi Utomo memberikan bantuan berupa pengajar dan mulai saat itu ridak hanya ilmu agama tetapi ilmu pengetahuan pun diajarkan. ${ }^{4}$ Lembaga ini diresmikan tanggal 1 Desember 1911. Melihat perkembangan lembaga pendidikan Islam Muhammadiyah yang sangat baik, banyak yang menyarankan agar Ahmad Dahlan mendirikan suatu organisasi yang kelak akan menjadi penerus setelah

\footnotetext{
4 A, A., \& J.F, F. (2013). Nizam Al-Mulk, Pengembang Sistem Pendidikan Kelas Dunia. Cssmora.
} 
Ahmad Dahlan tiada.

Setelah direnungkan dan mendapatkan orang-orang yang siap membantu, maka pada tanggal 18 Dzulhijah $1331 \mathrm{H}$ atau 18 Desember 1912 M didirikanlah oraganisasi yang bernama Muhammadiyah oleh Ahmad Dahlan. Dalam usaha mendapatkan pengakuan kepala pemerintah sebagai badan hukum, pada tanggal 20 Desember 1912, Muhammadiyah dibantu oleh Budi Utomo mengajukan surat permohonan kepada Gubernur Jenderal Hindia Belanda agar Muhammadiyah diberi izin resmi dan diakui sebagai suatu badan hukum. Untuk itu Gubernur Jenderal mengirimkan surat permintaan pertimbangan kepada Direktur Van Justitie, Adviseur Voor Inlandsche Zaken, Residen Yogyakarta dan Sri Sultan Hamengku Buwono VI. Setelah melalui proses yang cukup lama, akhirnya pemerintah Hindia Belanda mengakui Muhammadiyah sebagai badan hukum yang tertua dalam Gouvernement Besluit tanggal 22 Agustus 1914, Nomor 81, beserta lampiran statutennya dan berlaku mulai 22/23 Januari 1915.

Visi, Misi, Dan Tujuan Muhammadiyah sejak dari awal pendiriannya, Muhammadiyah telah menempatkan pendidikan sebagai salah satu media untuk mencapai tujuan organisasi ini. Lewat pendidikan, Muhammadiyah mampu mencerdaskan umat Islam dan bangsa Indonesia. Dalam rangka berperan aktif dalam dunia pendidikan, Muhammadiyah telah memutuskan visi, misi, dan tujuan pendidikan. Visi dan misi Muhammadiyah di bidang pendidikan menempati posisi strategis dalam rangka mencerdaskan umat Islam bangsa Indonesia. Untuk itu, agar maksud dan tujuan tersebut tercapai maka harus memiliki visi dan misi. Visi pendidikan Muhammadiyah adalah pengembangan intelektual peserta didik pada setiap jenis dan jenjang pendidikan yang dikelola oleh organisasi Muhammadiyah. Sedangkan misi pendidikan Muhammadiyah adalah menegakkan dan menjunjung tinggi agama Islam 
melalui dakwah Islam amar ma'ruf nahi munkar di semua aspek kehidupan. ${ }^{5}$

Tujuan Muhammadiyah di bidang pendidikan, selalu berhubungan dengan pandangan hidup yang dianut Muhammadiyah. Tujuan umum pendidikan Muhammadiyah secara resmi baru dirumuskan pada tahun 1936 saat kongres Muhammadiyah di Betawi. Dalam kongres tersebut tujuan Muhammadiyah dirumuskan sebagai berikut: ${ }^{6}$

a) Mengiringi anak-anak Indonesia menjadi orang Islam yang berkobarkobar semangatnya.

b) Badannya sehat, tegap bekerja.

c) Hidup tangannya mencari rezeki sendiri, sehingga kesemuanya itu memberi faedah yang besar dan berharga hingga bagi badannya dan juga masyarakat hidup bersama. Sebenarnya tujuan pendidikan Muhammadiyah sudah ada bersama dengan lahirnya pergerakan Muhammadiyah. Amir Hamzah mengungkapkan bahwa pendidikan Muhammadiyah menurut Ahmad Dahlan antara lain:

- baik budi, alim dalam agamis.

- luas pandangan, alim dalam ilmu-ilmu dunia.

- bersedia berjuang untuk kemajuan masyarakatnya.

Dalam konferensi di Pekajangan, Pekalongan tanggal 21-25 Juli 1955 rumusan tersebut diubah menjadi: "membentuk manusia muslim, berakhlak mulia, cakap, percaya pada diri sendiri dan berguna bagi masyarakat". Tujuan umum pendidikan Muhammadiyah tersebut dijabarkan ke dalam tujuan institusional sesuai dengan jenis dan tingkat sekolah tertentu. Kemudian tujuan pendidikan Muhammadiyah dioperasionalkan oleh Majelis Dikdasmen Muhammadiyah dengan menuangkannya dalam lima kualitas out-put Pendidikan Dasar dan Menengah Muhammadiyah, yakni:

1) Kualitas keIslaman

Sebagai institusi pendidikan diharapkan menjadi lembaga yang mencetak kader, sekolah/ madrasah/ pesantren Muhammadiyah

${ }^{5}$ Agus, Sukaca, Mengemban Misi Muhammadiyah, Suara Muhammadiyah, Yogyakarta, 2009.

6 Salam, Junus, KH. Ahmad Dahlan; Amal dan Perjuangannya, Al-Wasat, Tanggerang, 2009. 
haruslah menegaskan diri dalam menghasilkan peserta didik yang mengejawantahkan nilai-nilai Islam;

2) Kualitas keIndonesiaan

Rasa kebangsaan tumbuh jika setiap warga negara mematuhi hukum dan mengedepankan pelaksanaan kewajiban sebelum menuntut hak;

3) Kualitas Keilmuan

Kualitas keilmuan adalah tingkat kemampuan peserta didik menyerap pengetahuan yang diajarkan.

4) Kualitas kebahasaan

Kualitas kebahasaan adalah memiliki keterampilan dasar berbahasa asing khususnya bahasa Arab dan bahasa Inggris.

5) Kualitas keterampilan

Kualitas keterampilan merupakan kemampuan dalam mengoperasikan teknologi, khususnya teknologi informasi.

\section{METODOLOGI}

Jenis penelitian ini adalah penelitian eksplanatif kuantitatif. Menjelaskan beberapa variabel yang sudah di tetapkan maka jenis penelitian yang digunakan adalah penelitian ekspalanatif (explanatori research), yaitu penelitian yang menyoroti hubungan antara variabelvariabel penelitian dan menguji hipotesis yang telah dirumuskan sebelumnya. ${ }^{7}$ Teknik pengumpulan data melalui library research, mencari data dengan menggunakan sarana perpustakaan untuk mempelajari literatur dan buku-buku yang ada hubungannya dengan objek penelitian; field work reseach, mengadakan penelitian dengan menggunakan teknik observasi kepada semua responden yang telah ditetapkan. Wawancara, melakukan wawancara dengan BPH, Rektor, dekan, dosen, karyawan dan mahasiswa IMM serta alumni, berkaitan dengan permasalahan yang diteliti. Angket, untuk mendapatkan informasi dari audiens yang berkaitan dengan objek penelitian. Dokumentasi, mengumpulkan dokumen-dokumen, laporan dan catatan-catatan masalah yang diteliti.

\footnotetext{
7 Singarimbun, Masri dan Sofian Effendi, Metode Penelitian Survey. LP3ES. Jakarta, 1989.
} 


\section{PEMBAHASAN}

\section{A. Kader dalam Basis Norma Pengkaderan Muhammadiyah}

Kader ibarat jantung dalam suatu organisasi, jika kader lemah, maka lemah pula gerakan organisasi. Kader merupakan ujung tombak sekaligus tulang punggung kontinyuitas sebuah organisasi. Secara utuh kader adalah mereka yang telah tuntas dalam mengikuti seluruh pengkaderan formal, teruji dalam pengkaderan informal dan memiliki bekal melalui pengkaderan non formal. ${ }^{8}$ Keberadaan mereka bukan saja diharapkan dalam eksistensi organisasi tetap terjaga, melainkan juga diharapkan kader tetap akan membawa misi gerakan organisasi hingga paripurna.

Pengakaderan berarti proses bertahap dan terus-menerus sesuai tingkatan, capaian, situasi dan kebutuhan tertentu yang memungkinkan seorang kader dapat mengembangkan potensi akal, kemampuan fisik, dan moral sosialnya. Sehingga, kader dapat membantu orang lain dan dirinya sendiri untuk memperbaiki keadaan sekarang dan mewujudkan masa depan yang lebih baik sesuai dengan cita-cita yang diidealkan, nilai-nilai yang di yakini serta misi perjuangan yang diembannya.

Mengkader berarti mengembangkan karakter, sikap, etika, produktivitas dan kreatifitas para kader, maka pengkaderan bisa dikategorikan sebagai upaya mewujudkan misi, peran, dan fungsi dalam kehidupan pribadi dan organisasi serta kehidupan bermasyarakat, berbangsa dan bernegara. Melalui sistem pengkaderan maka diperluas pengetahuan dan wawasannya, ditempa keberanian dan karakternya, dikembangkan potensi dan kemampuan dalam dirinya, dipupuk kemandiriannya, serta diasah kesadaran, kepekaan, kehendak dan kecakapan sosialnya.

Sistem pengkaderan adalah sebuah gerakan yang rapi dan massif

8 Majelis Pendidikan Kader PP Muhammadiyah, Gerakan Muhammadiyah Berbasis Masjid dan Jamaah, MPK PPM, Yogyakarta, 2009. 
harus mengandalkan terbentuknya faktor-faktor produksi, dan distribusi. Tanpa menggunakan logika ini maka gerakan akan selalu terjebak pada heroisme sesaat dan kemudian mati tanpa meninggalkan apa-apa selain kemasyuran dan kebanggaan diri belaka. Katakanlah kita sedang akan membangun sebuah gerakan maka dimana wilayah-wilayah yang akan kita utamakan dan apa yang harus kita produksi serta menggunakan mekanisme seperti apa agar produk-produk kita tidak berhenti ditengah jalan. Rangkaian produksi-distribusi-perebutan ini adalah sebuah mata rantai yang tidak boleh putus, karena putusnya sebuah mata rantai ini berarti matinya dinamika sebuah gerakan atau setidaknya hanya akan menjadikan kader- kadernya tidak memiliki militansi untuk mengembangkan diri dan organisasi.

Kaderisasi mengisyaratkan tidak boleh adanya keterputusan antara satu proses dengan proses yang lainnya, karena antara satu dengan yang lainnya saling terkait, dan proses tersebut akan berjalan secara terus menerus. Hal ini paling tidak memberikan gambaran kepada kita bahwa sistem pengkaderan jangan hanya terfokus pada sisi internal saja, artinya mencetak kader sebanyak-banyaknya tetapi tidak tahu mau dibawa kemana kader tersebut. Untuk itu, sudah saatnya kita berfikir secara realistis, bahwa tanggung jawab pengkaderan secara organisasional juga terletak pada sisi pendistribusian kader pada medan-medan distribusi yang benar.

Dengan kata lain, pengkaderan hendaknya mencetak sosok kader yang memiliki pengetahuan luas dan mendalam, serta mempunyai jiwa dan tekad yang kuat dengan landasan pijak dan loyalitas yang teruji. Kader semacam ini dibutuhkan agar misi long life education baik dalam jangka panjang maupun jangka pendek dapat direalisasikan. Oleh karena itu pengkaderan di Perguruan Tinggi Muhammadiyah hendaklah memiliki sistem yang berkualitas, yang mampu mempengaruhi secara 
penuh kepada para kader dan sekaligus mempengaruhi lingkungan sehari-hari di perguruan tinggi Muhammadiyah. Mengingat faktor lingkungan tersebut maka harus mulai pembenahan serta menciptakan kualitaas keorganisasian yang lebih relevan dan sambung dengan misi Muhammadiyah.

a) Kader Muhammadiyah

Dalam sebuah organisasi dikenal istilah simpatisan, anggota, aktivis dan kader. Simpatisan adalah orang yang tertarik pada sebuah organisasi, namun tidak mengikatkan diri dalam organisasi tersebut. Anggota adalah simpatisan yang mengikatkan diri dalam organisasi dan ia terdaftar secara resmi/formal sebagai anggota, umumnya dibuktikan dengan kartu Anggota, namun tidak menjadi pengurus atau tidak terlibat dalam mengelola kegiatan-kegiatan organisasi. Aktivis adalah anggota yang menjadi pengurus dan terlibat dalam kegialan-kegiatan organisasi, namun tidak menjadi penggerak, hanya ikut bergerak. Sedangkan kader adalah akivis yang menjadi tenaga inti penggerak organisasi. ${ }^{9}$ Uraian diatas dapat digambarkan sebagai berikut:

\section{Gambar 1:}

Dinamika Pengkaderan Muhammadiyah

Keterangan:

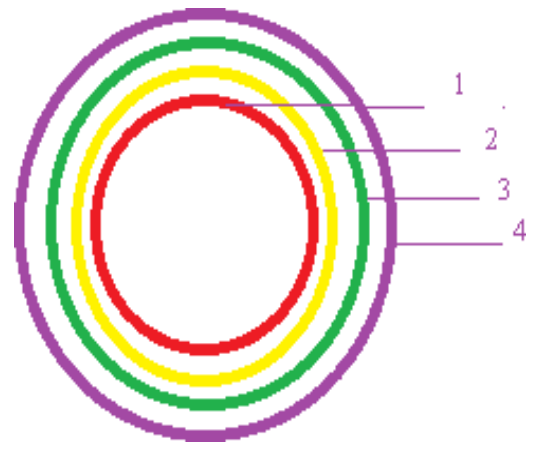

1. Lingkaran ke-l (paling dalam): kader

2. Lingkaran ke-2: akivis

3. Lingkaran ke-3: anggota

4. Lingkaran ke-4 (paling luar): simpatisan

${ }^{9}$ Haedar, Nasir, Dinamika Politik Muhamnadiyah, BIGRAF Publishing, Yogyakarta, 2000. 
Jadi yang dimaksud dengan kader adalah tenaga inti penggerak organisasi yang memiliki kualifikasi tertentu sebagai hasil dari proses perkaderan yang dialaminya. Mengutip yang dimaksud Haedar Nashir: yang dimaksud dengan kader Muhammadiyah adalah tenaga inti penggerak persyarikatan yang memiliki totalitas jiwa, sikap, pemikiran, wawasan, kepribadian dan keahlian sebagai pelaku atau subyek dakwah Muhammadiyah disegala lapangan kehidupan. Kader Muhammadiyah adalah tenaga inti penggerak persyarikatan yang lahir dari sebuah proses panjang dan sengaja disiapkan oleh Muhammadiyah agar kelak dapat membawa misi Muhammadiyah sebagai pelopor, pelangsung penyempurna usaha dan amal Muhammadiyah.

Dengan demikian seorang aktivis yang menjadi tenaga inti penggerak persyarikatan, tidak dapat disebut sebagai kader Muhamrnadiyah jika proses perkaderannya tidak melalui kaderisasi dalam tubuh Muhanmadiyah, dan ternyata belakangan kader semacam ini banyak ditemukan dalam tubuh Muhammadiyah. Akibatnya Muhammadiyah akan kehilangan ruh gerakan bahkan disorientasi gerakan, karena Muharnmadiyah digerakkan oleh orang-orang yang tidak atau kurang memahami misi gerakan Muhammadiyah.

\section{2) Problematika dalam Pengkaderan}

Muhammadiyah kini baru menyadari bahwa secara intemal telah terjadi krisis kader hampir disetiap jenjang kepengurusan, disadari bahwa selama ini kaderisasi belum berjalan secara optimal dengan melibatkan berbagai saluran dan sarana persyarikatan, bahkan terkesan masalah kaderisasi tidak terlalu mendapat perhatian yang serius dari pimpinan persyarikatan. Berbanding dengan pendidikan dan sosial (kesehatan) yang tampaknya dijadikan primadona.

Terjadinya krisis kader tersebut disebabkan oleh banyak faktor, antara lain: Pertama, semakin bertambahnya amal usaha Muhammadiyah, 
yang semakin banyak memerlukan tenaga penggerak. Kedua, kurang berfungsinya saluran-saluran kaderisasi dalam tubuh persyarikatan, yaitu saluran lembaga-lembaga pendidikan Muhammadiyah, saluran lenbaga Majelis Pendidikan Kader, dan saluran lembaga keluarga. Ketiga, kurangnya penjagaan atau pengikatan terhadap kader yang sudah mengikuti jenjang pengkaderan, sehingga kader tersebut berpindah pada orgaisasi yang lain dan berbalik memusuhi Muhammadiyah.

Dari problem pokok diatas yang menyebabkan terjadinya krisis kader, maka masalah-masalah kaderisasi dalam Muhammadiyah dapat dipetakan dan dan muncul adalah: ${ }^{10}$

(a) Rekruitmen personalia Pimpinan Ranting Muhammadiyah (PRM), Pimpinan Cabang Muhammadiyah (PCM), Pimpinan Daerah Muhammadiyah (PDM) dan Pimpinan Wilayah Muhammadiyah (PWM) serta pengelolaan amal usaha Muhammadiyah yang kurang tepat. Proses rekruitmen kadang hanya mempertimbangkan profesionalime dan kesediaan menjadi pengurus atau pengelola amal usaha, sementara pemahaman dan komitmen ke-Muhammadiyahan di nomor duakan atau bahkan diabaikal sama sekali. Misalnya, ada mantan pejabat atau tokoh tertentu yang belum pernah aktif di Muhammadiyah dipilih menjadi pengurus atau pimpinan amal usaha Muhammadiyah, demikian pula halnya dalam pengangkatan guru, dosen, tenaga medis dan karyawan pada amal usaha Muhammadiyah. Menurut Buya Syafi'i Ma'arif kita tidak boleh lerlalu terpukau atau merekayasa seseorang apakah pejabat atau bekas pejabat untuk didudukkan dalam posisi kepemimpinan, padahal belum mengenal budaya Muhammadiyah. ${ }^{11}$ Akibatya ada diantara mereka yang hanya mencari hidup bahkan menjadi "benalu" tanpa mau menghiduphidupkan Muhammadiyah. Disisi lain hal ini rnemang dapat dimaklumi karena ketiadaan kader, namun jika dibiarkan tanpa pembinaan justru akan jadi bom waku bagi Muhammadiyah itu sendiri;

(b)Lembaga-lembaga pendidikan Muhammadiyah sejak Taman Kanakkanak (TK), hingga Perguruan Tinggi (PT) tidak dijadikan sarana kaderisasi, tapi telah bergeser orientasinya sebagai wadah pencetak

\footnotetext{
10 W. Hasyim, Mustofa, Ranting itu Penting, Pustaka SM, Yogyakarta, 2000.

11 Ahmad Syafi'I, Ma'arif, Independensi Muhammadiyah di Tengah Pergumulan Pemikiran Islam dan Politik, Pustaka Cidesindo, Jakarta, Hlm, 141.
} 


\section{Mappanyompa \& Imawanto| Problematika Pengkaderan di Perguruan Tinggi \\ Muhammadiyah....}

tenaga kerja, bahkan dijadikan sarana penghasil uang, sementara induknya (Muhammadiyah) tetap meminta-minta sumbangan kepada warganya jika akan melaksanakan kegiatan Ikatan Pelajar Muhammadiyah (IPM) dan Ikatan Mahasiswa Muhammadiyah (IMM) sebagai bagian dari sarana kaderisasi ibarat pepatah "bagai kerakap tumbuh diatas batu, hidup segan mati tak mau" padahal ini adalah organisasi otonom (ORTOM) yang berada dalam lembaga pendidikan Muhammadiyah sendiri;

(c) Para pengurus, pimpinan amal usaha dan elit Muhammadiyah enggan mengkader atau melibaikan anak-anaknya dalam kegiatan Muhammadiyah, sementa banyak orang lain terus dipicu dan dipacu untuk aktif di Muhammadiyah, bahkan mungkin ada anak para elit Muhammadiyah yang tidak pernah shalat di masjid Muhammadiyah. Haedar Nashir menyatakan bahwa merupakan hal yang ganjil jika para tokoh Muhammadiyah sibuk sepanjang hari berkiprah mengembangkan Muhammadiyah dan mengkader anak orang lain, sementara anak- anaknya sendiri tidak dibina ke arah itu. ${ }^{12}$

(d)Belum optimalnya fungsi dan peran Majelis Pendidikan Kader pada hampir setiap jenjang kepengurusan. Hal ini disamping karena lemahnya SDM yang mengelola majelis ini, juga disebabkan kurangnya perhatian pimpinan persyarikatan baik berupa moril maupun materil, berbeda dengan Majelis Pendidikan Dasar dan Menengah atau Majelis PKS yang disupport oleh hampir seluruh pimpinan persyarikatan. Masalah- masalah yang dipaparkan diatas bukan sesuatu yang berdiri sendiri- sendiri, tetapi saling berkaitan satu sama lain sebagai sebuah untaian mata rantai.

Dari pemetaan dan analisis masalah diatas sesungguhnya tergambar strategi kaderisasi yang harus dilakukan oleh Muhammadiyah, yakni sebagai berikut:

(1)Pola rekruitmen pengelola amal usaha Muhammadiyah (dosen, lembaga medis, karyawan) harus melalui atau dengan persetujuan Pimpinan Muhammadiyah pada level masing-masing, kalaupun yang bersangkutan bukan berasal dari kalangan Muhammadiyah, maka harus ada Memorandun of Understanding (MOU) untuk mengembangkan Muhammadiyah.

(2)Jalur kaderisasi pendidikan, Majelis Pendidikan Kader:13

12 Nashir, Haedar, Revitalisasi Gerakan Muhammadiyah, BIGRAF Publishing, Yogyakarta, 2000, Hlm 22.

13 Tim MPK PP Muhammadiyah, Sistem Perkaderan Muhammadiyah, MPK PP Muhammadiyah, Yogyakana, 2007. 
Pertama, melalui jalur pendidikan. Muhammadiyah telah memiliki sekolah-sekolah khusus seperti Muallimin dan Muallimat serta sekolahsekolah umum yang kelahirannya merupakan alternatif pendidikan Islam modern. Lembaga-lembaga ini seyogyanya dijadikan wadah pembinaan kader dan hal tersebut selama ini hanya berjalan di Muallimin dan Muallimat Muhammadiyah, Pondok Hajjah Nuriyyah Shobron, Pendidikan Ulama Tarjih Muhammadiyah di Yogyakarta atau Pondok Pesantren Ulama Tarjihdi Malang. Namun tidak semua daerah atau cabang Muhammadiyah diberikan jatah untuk mengirimkan anak didiknya ke lembaga-tembaga pendidikan tersebut. Sudah saatnya Pimpinan Pusat memberikan jatah formasi dan biaya pendidikan kepada setiap PDM dau PCM disemuah daerah, untuk mengirimkan utusannya setiap tahun minimal 2 (dua) orang untuk menempuh pendidikan lembaga-lembaga tersebut.

Disamping itu lembaga-lembaga pendidikan Muhammadiyah seluruh wilayah, daerah dan cabang harus memberikan perhatian yang lebih kepada IPM dan IMM sebagai wadah pembinaan kader, antara lain memberikan fasilitas sarana dan prasarana termasuk pendanaan. Sementara ini ortom tersebut ada dan hidup di lembaga pendidikan Muhammadiyah, namun kurang mendapat perhatian dan dukungan yang sungguh-sungguh dari pengelola amal usaha Muhammadiyah. IMM misalnya harus menyatu kegiatannya dengan lembaga-lembaga kemahasiswaan intra kampus. Agar kegiatan ortom ini mendapat dukungan semua pihak, maka seluruh dosen serta staf tata usaha harus diberikan pemahaman yang kontinyu tentang Muhammadiyah misalnya melalui pengajian-pengajian rutin yang kehadiran mereka menjadi salah satu pertimbangan dalam memberikan kondite kepegawaian. Terlebih lagi dosen yang mengajar mata kuliah pendidikan Agama Islam dan Kemuhammadiyahan mutlak harus orang yang benar-benar aktif dan berideologi Muhammadiyah tidak hanya sekedar mengaku atau memiliki Kartu Anggota Muhammadiyah, apalagi mereka yang samasekali tidak berideologi Muhammadiyah. Bagaimana mungkin dari lembaga pendidikan Muhammadiyah akan lahir kader yang berideologi Muhammadiyah jika dalam mata kuliah Pendidikan Agama Islam dan Kemuhammadiyahnya justru diajarkan paham yang bertentangan dengan paham Muhammadiyah.

Kedua, melalui jalur Majelis Pendidikan kader, pada tingkat pusat barang kali majelis ini telah menjalankan tugas dan fungsinya dengan baik, namun di tingkat wilayah, apalagi didaerah dan cabang, sebagian besar MPK belum dapat melakukan tugas dan fungsinya secara optimal, tentu dengan berbagai kendala yang dihadapi, antara lain kurangnya ketersediaan SDM, kurangnya sumber dana, kurangnya perhatian Pimpinan Muhammadiyah dan lain-lain. 
Disamping melaksanakan pengkaderan melalui kegiatan pelatihan dan sebagainya, sesungguhnya MPK dapat melakukan perkaderan dengan melakukan koordinasi dan kerjasama dengan hampir seluruh majelis yang ada pada struktur pimpinan Muhammadiyah dari pimpinan amal usaha Muhammadiyah, misalnya perkaderan ulama tarjih, perkaderan muballigh, perkaderan ortom-ortom di wilayahnya, memperakarsai sosialisasi pemahaman kemuhammadiyahan kepada para anggota pimpinan dan kepada seluruh pengelola amal usaha Muhammadiyah. Dapat pula MPK bekerjasama dengn Majelis Dikdasmen dan Majelis PKS dalam penysunan pedoman atau aturan rekruitmen tenaga dosen tenaga kesehatan, pengelola panti asuhan, dan sebagainya.

Ketiga, melalui jalur keluarga, lembaga keluaga sesungguhnya memainkan peran yang cukup besar dalam mempersiapkan kaderkader Muhammadiyah. Dari keluarga-keluarga warga Muhammadiyah seyogyanya perkaderan dimulai, lebih-lebih bagi keluarga pimpinan Muhammadiyah. Pengkaderan tesebut dapat dilakukan dengan cara memberikan pemahaman Islam yang benar sesuai Al-Qur'an ${ }^{14}$ dan AsSunnah maqbulah. Membina pratik ibadah yang benar sesuai putusan Tarjih serta melibatkan anak-anaknya dalam kegiatan-kegiatan Muhammadiyah.

\section{SIMPULAN}

Kaderisasi menempati posisi yang sangat strategis bagi kelangsungan hidup Muhammadiyah sebagai sebuah persyarikatan dan gerakan Islam dakwah amar ma'ruf nahi munkar. Sudah saatnya kaderisasi mendapat perhatian yang sungguh-sungguh dari segenap pimpinan Muhammadiyah dan pimpinan amal usaha Muhammadiyah, terutama di Nusa Tenggara Barat yang kondisinya tentu berbeda dengan daerah lain. Dilandasi oleh niat yang tulus untuk menghidup-hidupkan Muhammadiyah dan tidak semata mencari hidup dalam Muhammadiyah sebagaimana pesan sang pendirinya almarhum KH. Ahmad Dahlan. ${ }^{15}$ Jangan sampai terjadi di kemudian hari bahwa ada orang yang tidak

\footnotetext{
14 Al-Qur'anul Qariim

15 Mulkam, Munir, Abdul, Kisah dan Pesan KH. Ahmad Dahlan (Yogyakarta: Scripta Perennia), 2005.
} 
diketahui asal-usul kemuhammadiyahannya justru menjadi pemain inti di Muhammadiyah atau amal usaha Muhammadiyah, sementara orang yang sudah lama berkiprah dan tidak diragukan komitmen kemuhammadiyahannya justru hanya jadi penonton.

\section{DAFTAR PUSTAKA}

\section{Buku}

Al-Qur'anul Karim

A, A., \& J.F, F. (2013). Nizam Al-Mulk, Pengembang Sistem Pendidikan Kelas Dunia. Cssmora.

Ahmad Syafi'I, Ma'arif, 2000, Independensi Muhammadiyah di Tengah Pergumulan Pemikiran Islam dan Politik, Pustaka Cidesindo, Jakarta.

Agus, Sukaca, 2009, Mengemban Misi Muhammadiyah, Suara Muhammadiyah, Yogyakarta.

Haedar, Nasir, 2000, Revitalisasi Gerakan Muhammadiyah, BIGRAF Publishing, Yogyakarta. 2000, Dinamika PolitikMuhammadiyah, BIGRAF Publishing, Yogyakarta.

Hambali, Hamdan, 2006, Ideologi dan Stategi Muhammaadiyah, Suara Muhammadiyah, Yogyakarta.

Mulkam, Munir, 2005, Abdul, Kisah dan Pesan KH. Ahmad Dahlan, Scripta Perennia, Yogyakarta.

Majelis Pendidikan Kader PP Muhammadiyah, 2009, Gerakan Muhammadiyah Berbasis Masjid dan Jamaah, MPK PPM, Yogyakarta.

M. Amin, Rais, 1998, Tauhid Sosial, Formula Menggempur Kesenjangan, Mizan, Bandung.

Pasha, Musthafa Kamal dan Darban, Ahmad Adaby, 2000, Muhammadiyah 
sebagai Gerakan Islam (dalam Perspektif Historis dan Ideologis), LPPI UMY, Yogyakarta.

Salam, Junus, 2009, KH. Ahmad Dahlan; Amal dan Perjuangannya, Al-Wasat, Tanggerang,

Singarimbun, Masri dan Sofian Effendi, 1989, Metode Penelitian Survey. LP3ES. Jakarta.

Tim MPK PP Muhammadiyah, 2007, Sistem Perkaderan Muhammadiyah, MPK PP Muhammadiyah, Yogyakana.

W. Hasyim, Mustofa, 2000, Ranting itu penting, Pustaka SM, Yogyakarta. 